\title{
National findings from the Tracks survey of people who inject drugs in Canada, Phase 4, 2017-2019
}

\section{Jill Tarasuk ${ }^{1 \star}$, Jingxuan Zhang ${ }^{1}$, Anaïs Lemyre ${ }^{1}$, François Cholette ${ }^{2}$, Maggie Bryson ${ }^{1}$, Dana Paquette $^{1}$}

\section{Abstract}

Background: The Tracks survey of people who inject drugs (PWID) collected data in 14 sentinel sites across Canada (2017-2019).

Objective: To describe the prevalence of human immunodeficiency virus (HIV) and hepatitis C and associated risk behaviours and to examine trends over time.

Methods: Information regarding socio-demographics, social determinants of health, use of prevention services and testing, drug use, risk behaviours, and HIV and hepatitis $C$ testing, care and treatment was collected through interviewer-administered questionnaires. Biological samples were tested for HIV, hepatitis $C$ antibodies and hepatitis C ribonucleic acid (RNA). Descriptive statistics were calculated and trends over time were assessed.

Results: Of the 2,383 participants, $65.6 \%$ were cisgender male, $42.2 \%$ were Indigenous, $48.0 \%$ completed some high school or less, $62.6 \%$ lived in unstable housing and $75.7 \%$ had ever been incarcerated. Average age was 40.1 years. The majority experienced stigma and discrimination (88.7\%) and physical, sexual and/or emotional abuse in childhood (85.0\%) or with a sexual partner $(75.9 \%)$. The majority reported use of a needle/syringe distribution program $(90.1 \%)$ and tested for HIV (90.5\%) and hepatitis C (90.9\%).

Among participants who had ever had sex, the majority (59.2\%) reported inconsistent condom use during vaginal and/or anal sex with a casual sex partner. Prevalence of HIV was $10.3 \%$ (82.9\% were aware of infection status) and many (36.9\%) were hepatitis C RNA-positive $(50.1 \%$ were aware of infection status).

Most surveillance indicators remained relatively stable from Phase 1 to Phase 4. Changes were found in substances used, and improvements were noted related to HIV and hepatitis C prevalence and care cascade indicators.

Conclusion: Many PWID in Canada were living in unstable housing and experienced high levels of stigma and discrimination. Prevalence of HIV and hepatitis C was high in some areas. These findings contribute to the evidence base used to inform targeted prevention and control measures.

Suggested citation: Tarasuk J, Zhang J, Lemyre A, Cholette F, Bryson M, Paquette D. National findings from the Tracks survey of people who inject drugs in Canada, Phase 4, 2017-2019. Can Commun Dis Rep 2020;46(5):13848. https://doi.org/10.14745/ccdr.v46i05a07

Keywords: HIV, hepatitis C, people who inject drugs, drug use, injecting behaviours, sexual risk practices, overdose, infection status, testing, care and treatment
This work is licensed under a Creative Commons Attribution 4.0 International License.

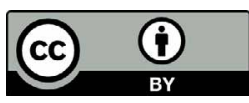

Affiliations

${ }^{1}$ Centre for Communicable Diseases and Infection Control, Public Health Agency of Canada, Ottawa, ON

${ }^{2}$ National Mircrobiology Laboratory, Public Health Agency of Canada, Winnipeg, MB

${ }^{\star}$ Correspondence:

jill.tarasuk@canada.ca 


\section{Introduction}

People who inject drugs (PWID) represent an important group at risk for human immunodeficiency virus (HIV) and hepatitis $C$ in Canada. It has been estimated that, of the 2,165 new HIV infections in 2016, the proportion attributed to injection drug use was $11.3 \%$. This value had not decreased since the 2014 estimate of $11.2 \%$ (1). In North America, the burden of disease of hepatitis $C$ attributable to injecting drug use is greater than for HIV, and was estimated to be $81 \%$ in 2013 (2). In Canada, HIV and hepatitis $C$ antibody prevalence was high among PWID surveyed in $2010-2012$ (11.2\% and 68\%, respectively) (3). These findings underscore the need for prevention and treatment efforts to mitigate HIV and hepatitis $\mathrm{C}$ morbidity and mortality in this population. Integrated bio-behavioural surveillance, an established World Health Organization (WHO)/Joint United Nations Programme on HIV/AIDS (UNAIDS) globally-endorsed approach (4), is critical to informing response and to guiding public health interventions. This surveillance provides information about risk practices and health-seeking behaviours among the populations most at risk for HIV and is necessary to better understand the factors driving transmission.

The Public Health Agency of Canada (PHAC), in conjunction with provinces and territories including regional and/or local public health partners, monitors trends in the prevalence of HIV and hepatitis $C$ and associated risk factors in key populations, such as PWID, through the Tracks Surveillance Systems. The Tracks survey of PWID (formerly I-Track) involves repeated crosssectional surveys at selected sites across Canada. It was first implemented in 2003-2005 (Phase 1) in seven sentinel sites. This was followed by three subsequent data collection periods, including the most recent survey, Phase 4 (2017-2019), in 14 sentinel sites (Appendix 1).

The objective of this report is to present national surveillance findings from Phase 4 of the Tracks survey of PWID in Canada, conducted between January 1, 2017 and May 9, 2019, at participating sentinel sites in Canada. Findings include socio-demographic characteristics, social determinants of health, use of prevention services and testing, drug use and experiences with overdoses, sexual risk behaviours and HIV and hepatitis $C$ care cascade, prevalence and awareness of infection status. Selected indicators from Phase 1 to Phase 4 of the Tracks survey of PWID are also presented to describe trends over time.

\section{Methods}

\section{Data source and sampling methods}

The data presented in this report are from the Tracks survey of PWID in Canada. The Tracks survey of PWID makes use of venue-based sampling, in which participants are recruited from settings in which they are likely to gather, most often, but not limited to, needle and syringe distribution programs. Individuals who had injected drugs six months prior to recruitment and who met the minimum age to provide consent, which was determined at each site according to local research ethics requirements, were eligible to participate in the survey. Eligible and consenting participants completed an interviewer-administered questionnaire and provided a biological sample in the form of a dried blood spot (DBS) specimen (or oral fluid exudate in the SurvUDI network sites).

The surveillance protocol and questionnaire were approved by the Health Canada/PHAC Research Ethics Board, and by local research ethics boards at each sentinel site where required. The same sampling and recruitment strategies and core questionnaire, with minor revisions, were used across all four phases to ensure comparability over time. Survey methods are described in more detail elsewhere (3).

\section{Sentinel site selection}

Sentinel sites were selected based on consultations with provincial/territorial representatives, who considered the epidemiology of HIV, hepatitis $C$ and drug use and associated harms. Given this assessment, participating sentinel sites varied by phase of the Tracks Survey of PWID (Appendix 1). Data collection in Ottawa (Ontario) and in the province of Quebec was coordinated by the SurvUDI network (5). The SurvUDI network sites were divided into four geographical zones for the Phase 4-specific analyses (see Appendix 1).

\section{Interviewer-administered questionnaire}

The Tracks PWID questionnaire collects information about socio-demographic characteristics, social determinants of health, use of health and prevention services (including testing), drug use and injecting behaviours, sexual behaviours and care and treatment for HIV and hepatitis C. The questionnaire was first developed for a pilot phase by an expert working group to establish face validity. To ensure comparability, each subsequent phase retained most national-level questions to monitor change over time.

The Phase 4 questionnaire included a limited number of revisions, including new national-level questions that addressed gender identity, financial strain, mental health status, experiences of stigma and discrimination, physical, sexual and/or emotional abuse, borrowing used non-injection drug paraphernalia, overdose-related experiences, use of harm reduction services, condomless sex at last paid sex, substance use before or during sex, adherence to antiretroviral treatment and viral load status.

\section{Biological sample}

Dried blood spot samples were tested for HIV (antibody and antigen) and hepatitis C (antibody and RNA). Participants were not informed of their laboratory test results because no identifying information was collected to ensure participant anonymity. Sentinel sites were asked to provide on-site testing (e.g. point of care testing, full phlebotomy) during recruitment 
times so that participants who were not aware of their status could get tested, should they wish. Where on-site testing was not feasible, participants were referred to local testing sites and/or health care services. Updated laboratory testing algorithms for DBS were introduced in Phase 4 (see Appendix 2). Testing algorithms for SurvUDI samples are found in Appendix 2.

\section{Analysis}

Descriptive statistics for selected indicators were computed with SAS Enterprise Guide 7.1. Selected indicators from Phase 1 to Phase 4 were compared to examine trends over time. Small cell counts were assessed to determine the risk of identifying individual participants, and were left in when it was determined that there was no risk of reidentification, as per PHAC's Directive for the collection, use and dissemination of information relating to public health (PHAC, 2013, unpublished document). Participants who responded as "not stated", "don't know" or "refused" were excluded from each individual analysis.

\section{Results}

Sample sizes for Phase 1, Phase 2 and Phase 3 were 2,986, 2,982 and 2,687 , respectively. A total of 2,383 individuals were eligible and consented to participate in the Phase 4 survey, among whom 2,379 (99.8\%) completed a questionnaire and 2,162 (90.7\%) provided a biological sample. Findings for selected indicators by socio-demographic characteristic and social determinants of health of participants are provided in Supplemental tables A (prevention and testing indicators), B (injecting behaviours and drug use), C (sexual risk behaviours) and D (selected indicators by Phase).

\section{Socio-demographic characteristics}

In Phase 4, 65.6\% identified their gender as cisgender male, $32.7 \%$ as cisgender female and $1.0 \%$ as transfeminine (i.e. those assigned male at birth who identified with either female or a non-binary gender) and $0.7 \%$ transmasculine (i.e. those assigned female at birth who identified with either male or a non-binary gender) (Table 1). The average age was 40.1 years (Supplemental table D).

Of all participants, $42.2 \%$ identified as Indigenous, of whom $82.9 \%$ identified as First Nations, $14.9 \%$ Métis or $2.2 \%$ Inuit. Among all Indigenous participants, $13.8 \%$ reported living in a First Nations, Métis or Inuit community at the time of the interview. The proportion of participants who identified as other ethnicities was $57.8 \%$ of whom the majority (96.3\%) identified as White. Most demographics stayed relatively stable over the four phases, while the average age increased slightly, as did the proportion who self-identified as Indigenous (Supplemental table D).

\section{Social determinants of health}

Among Phase 4 participants, just under half (48.0\%) had completed some high school or less and a large proportion
Table 1: Socio-demographic characteristics of participants in the Tracks survey of people who inject drugs in Canada, Phase 4, 2017-2019 $(n=2,383)$

\begin{tabular}{|c|c|c|c|c|}
\hline \multicolumn{2}{|c|}{$\begin{array}{l}\text { Socio-demographic } \\
\text { characteristics }\end{array}$} & \multirow{2}{*}{$\begin{array}{l}\text { n } \\
775\end{array}$} & \multirow{2}{*}{$\begin{array}{r}\text { Total } \\
\text { 2,372 }\end{array}$} & \multirow{2}{*}{$\begin{array}{l}\% \\
32.7\end{array}$} \\
\hline Gender identity & $\begin{array}{l}\text { Cisgender } \\
\text { female }\end{array}$ & & & \\
\hline & Cisgender male & 1,556 & 2,372 & 65.6 \\
\hline & Transfeminine $e^{b}$ & 24 & 2,372 & 1.0 \\
\hline & Transmasculine $^{c}$ & 17 & 2,372 & 0.7 \\
\hline \multirow[t]{4}{*}{ Age group } & $\begin{array}{l}\text { Younger than } 25 \\
\text { years }\end{array}$ & 161 & 2,378 & 6.8 \\
\hline & 25 to 39 years & 1,058 & 2,378 & 44.5 \\
\hline & 40 to 54 years & 895 & 2,378 & 37.6 \\
\hline & 55 years or older & 264 & 2,378 & 11.1 \\
\hline \multirow[t]{14}{*}{ Sentinel site } & Whitehorse, YK & 49 & 2,383 & 2.1 \\
\hline & $\begin{array}{l}\text { Central and } \\
\text { Northern } \\
\text { Vancouver } \\
\text { Island, BC }\end{array}$ & 179 & 2,383 & 7.5 \\
\hline & Prince Albert, SK & 184 & 2,383 & 7.7 \\
\hline & Regina, SK & 205 & 2,383 & 8.6 \\
\hline & Winnipeg, MB & 181 & 2,383 & 7.6 \\
\hline & $\begin{array}{l}\text { Thunder Bay, } \\
\text { ON }\end{array}$ & 200 & 2,383 & 8.4 \\
\hline & London, ON & 206 & 2,383 & 8.6 \\
\hline & Hamilton, ON & 157 & 2,383 & 6.6 \\
\hline & $\begin{array}{l}\text { Ottawa, ON and } \\
\text { the region of } \\
\text { Outaouais, } \mathrm{OC}\end{array}$ & 200 & 2,383 & 8.4 \\
\hline & Montréal, OC & 200 & 2,383 & 8.4 \\
\hline & Québec, QC & 125 & 2,383 & 5.3 \\
\hline & $\begin{array}{l}\text { Other urban } \\
\text { sites in Quebec }^{d}\end{array}$ & 167 & 2,383 & 7.0 \\
\hline & New Brunswick & 200 & 2,383 & 8.4 \\
\hline & Newfoundland & 130 & 2,383 & 5.5 \\
\hline \multirow[t]{2}{*}{$\begin{array}{l}\text { Indigenous } \\
\text { status }\end{array}$} & $\begin{array}{l}\text { First Nations, } \\
\text { Métis, or Inuit }\end{array}$ & 997 & 2,360 & 42.2 \\
\hline & Other ethnicity & 1,363 & 2,360 & 57.8 \\
\hline \multirow{2}{*}{$\begin{array}{l}\text { Living in a FN, } \\
\text { Métis or Inuit } \\
\text { communitye }\end{array}$} & No & 802 & 930 & 86.2 \\
\hline & Yes & 128 & 930 & 13.8 \\
\hline \multicolumn{5}{|c|}{$\begin{array}{l}\text { Abbreviations: BC, British Columbia; FN, First Nations; MB, Manitoba; ON, Ontario; QC, Québec } \\
\text { SK, Saskatchewan; YK, Yukon } \\
\text { a Total represents total counts for the corresponding indicator excluding "don't know", "refused" } \\
\text { and "not stated" values } \\
\text { b Transfeminine included those assigned male at birth who identified with either female or a } \\
\text { non-binary gender } \\
\text { "Transmasculine included those assigned female at birth who identified with either male or a } \\
\text { non-binary gender } \\
\text { dOther urban sites in the province of Quebec included Abitibi-Témiscamingue, Montérégie, } \\
\text { Saguenay-Lac Saint-Jean, Eastern Townships and Mauricie-Central Québec } \\
\text { "This question was asked among Indigenous participants only }\end{array}$} \\
\hline
\end{tabular}


(86.0\%) experienced financial strain (i.e. difficulty making ends meet) in the 12 months prior to the interview (Table 2). Overall, $62.6 \%$ of participants lived in unstable housing in the six months prior to the interview and $75.7 \%$ reported having ever been incarcerated. A large proportion (84.0\%) reported their mental health as "fair to excellent" and $16.0 \%$ reported poor mental health status. Among Indigenous participants, $83.1 \%$ had attended a residential school themselves or had a family member who had attended a residential school.

Table 2: Social determinants of health of participants in the Tracks survey of people who inject drugs in Canada, Phase 4, 2017-2019 ( $n=2,383)$

\begin{tabular}{|c|c|c|c|c|}
\hline \multicolumn{2}{|c|}{$\begin{array}{c}\text { Social determinants of } \\
\text { health }\end{array}$} & \multirow{2}{*}{$\begin{array}{l}\mathbf{n} \\
1,139\end{array}$} & \multirow{2}{*}{$\begin{array}{l}\text { Total }^{a} \\
2,373 \\
\end{array}$} & \multirow{2}{*}{$\begin{array}{l}\% \\
48.0\end{array}$} \\
\hline $\begin{array}{l}\text { Education, } \\
\text { highest level }\end{array}$ & $\begin{array}{l}\text { Less than } \\
\text { high school }\end{array}$ & & & \\
\hline & $\begin{array}{l}\text { Finished high } \\
\text { school }\end{array}$ & 621 & 2,373 & 26.2 \\
\hline & $\begin{array}{l}\text { More than } \\
\text { high school }\end{array}$ & 613 & 2,373 & 25.8 \\
\hline \multirow{2}{*}{$\begin{array}{l}\text { Experienced } \\
\text { financial strain } \\
\text { past } 12 \text { months }\end{array}$} & No & 207 & 1,479 & 14.0 \\
\hline & Yes & 1,272 & 1,479 & 86.0 \\
\hline \multirow[t]{2}{*}{$\begin{array}{l}\text { Housing status, } \\
\text { past six months }\end{array}$} & $\begin{array}{l}\text { Unstable } \\
\text { housing }^{c}\end{array}$ & 1,486 & 2,374 & 62.6 \\
\hline & $\begin{array}{l}\text { Stable } \\
\text { housing }\end{array}$ & 888 & 2,374 & 37.4 \\
\hline \multirow{2}{*}{$\begin{array}{l}\text { Ever } \\
\text { incarcerated }^{d}\end{array}$} & No & 422 & 1,736 & 24.3 \\
\hline & Yes & 1,314 & 1,736 & 75.7 \\
\hline \multirow[t]{2}{*}{ Mental health } & $\begin{array}{l}\text { Fair to } \\
\text { excellent }\end{array}$ & 1,401 & 1,668 & 84.0 \\
\hline & Poor & 267 & 1,668 & 16.0 \\
\hline \multirow{2}{*}{$\begin{array}{l}\text { Experience } \\
\text { of stigma and } \\
\text { discrimination } \\
\text { ever }\end{array}$} & No & 166 & 1,464 & 11.3 \\
\hline & Yes & 1,298 & 1,464 & 88.7 \\
\hline \multirow{2}{*}{$\begin{array}{l}\text { Experience } \\
\text { of childhood } \\
\text { physical, } \\
\text { sexual, and/ } \\
\text { or emotional } \\
\text { abuse }\end{array}$} & No & 220 & 1,463 & 15.0 \\
\hline & Yes & 1,243 & 1,463 & 85.0 \\
\hline \multirow{2}{*}{$\begin{array}{l}\text { Experience of } \\
\text { sexual partner } \\
\text { physical, } \\
\text { sexual, and/ } \\
\text { or emotional } \\
\text { abuse }\end{array}$} & No & 351 & 1,458 & 24.1 \\
\hline & Yes & 1,107 & 1,458 & 75.9 \\
\hline \multicolumn{5}{|c|}{$\begin{array}{l}\text { "Total represents total counts for the corresponding indicator excluding "don't know", "refused" } \\
\text { and "not stated" values } \\
\text { b Defined as ever having difficulty making ends meet in the year prior to the interview } \\
\text { c Unstable housing included living in a hotel or motel room, rooming or boarding house, shelter } \\
\text { or hostel, transition or halfway house, psychiatric institution or drug treatment facility, public place } \\
\text { or correctional facility } \\
\text { d Only partial data available at the SurvUDI network sites } \\
\text { e Defined as ever experienced any stigma or discrimination (e.g. avoidance, pity, blame, shame, } \\
\text { rejection, verbal abuse or bullying based on racial or cultural background, hepatitis C status, HIV } \\
\text { status, sexual orientation, use of drugs or alcohol or sex work }\end{array}$} \\
\hline
\end{tabular}

Experiences of stigma and discrimination (related to racial or cultural background, hepatitis C status, HIV status, sexual orientation, use of drugs or alcohol or sex work) were reported by the majority of participants (88.7\%). Large proportions of participants had experienced physical, sexual and/or emotional abuse in childhood (85.0\%) or with a sexual partner $(75.9 \%)$.

Over the past four phases, the social determinant indicators stayed relatively stable with the exception of an increase in the proportion reporting living in unstable housing in the six months prior to the interview (51.1\%-62.6\%) (Supplemental table D).

\section{Use of prevention services and testing}

In Phase 4, the majority of participants $(90.1 \%)$ reported using a needle and syringe distribution program in the 12 months prior to the interview, with lower proportions reporting use of methadone, suboxone or other opioid substitution therapy $(47.3 \%)$ and use of a supervised injection or consumption site (13.5\%). The majority of participants reported ever testing for HIV (90.5\%) and hepatitis C (90.9\%) (Table 3). Some (14.3\%) of the participants had heard about preexposure prophylaxis (PrEP). Among participants who did not report an HIV diagnosis, $0.3 \%$ had used PrEP in the 12 months prior to the interview to reduce the risk of contracting HIV. The proportion of participants who had ever tested for HIV (90.0\%-92.9\%) and hepatitis C (87.5\%-91.3\%) was high and varied slightly across all phases (Supplemental table D).

Table 3: Use of prevention services and testing for HIV and hepatitis $\mathrm{C}$ of participants in the Tracks survey of people who inject drugs in Canada, Phase 4, 2017-2019 $(n=2,383)$

\begin{tabular}{|c|c|c|c|}
\hline Use of prevention services and testing & $\mathbf{n}$ & Total $^{a}$ & $\%$ \\
\hline $\begin{array}{l}\text { Use of a needle and syringe distribution } \\
\text { program, past } 12 \text { months }\end{array}$ & 1,490 & 1,653 & 90.1 \\
\hline $\begin{array}{l}\text { Use of a supervised injection or consumption } \\
\text { site, past } 12 \text { months } s^{b}\end{array}$ & 223 & 1,652 & 13.5 \\
\hline $\begin{array}{l}\text { Use of methadone, suboxone or other } \\
\text { opioid substitution therapy, past } 12 \text { months }\end{array}$ & 780 & 1,650 & 47.3 \\
\hline Tested for HIV, ever & 2,080 & 2,299 & 90.5 \\
\hline Tested for HCV, ever & 2,086 & 2,296 & 90.9 \\
\hline
\end{tabular}

\section{Injecting behaviours}

In Phase 4, over one-third of participants (38.1\%) reported injecting daily in the month prior to the interview and over half $(52.7 \%)$ reported injecting in a public space in the six months prior to the interview. Overall, $11.6 \%$ of participants injected with used needles and/or syringes in the six months prior to the interview, of whom the majority (85.2\%) borrowed needles and/ or syringes from people who they knew well (i.e. family, friends or sex partners). Over one-third (38.0\%) injected with other used injection equipment such as water, filters, cookers, tourniquets, swabs or acidifiers in the six months prior to the interview. Among those who borrowed used equipment, the majority (82.9\%) reported borrowing from people they knew well. More than half of participants (56.0\%) borrowed used non-injection 
drug paraphernalia such as straws, dollar bills, or pipes in the six months prior to the interview (Table 4).

Table 4: Injecting behaviours of participants in the Tracks survey of people who inject drugs in Canada, Phase 4, 2017-2019 $(n=2,383)$

\begin{tabular}{|l|r|r|c|}
\hline \multicolumn{1}{|c|}{ Injecting behaviours } & \multicolumn{1}{|c|}{ n } & Total & \multicolumn{1}{c|}{$\%$} \\
\hline Injected daily in the past month & 822 & 2,155 & 38.1 \\
\hline $\begin{array}{l}\text { Injected drugs in a public space, past six } \\
\text { months }\end{array}$ & 1,243 & 2,357 & 52.7 \\
\hline $\begin{array}{l}\text { Borrowed used needles and/or syringes, } \\
\text { past six months }\end{array}$ & 271 & 2,339 & 11.6 \\
\hline $\begin{array}{l}\text { Borrowed used needles and/or syringes } \\
\text { from people known wellc, past six months }\end{array}$ & 224 & 263 & 85.2 \\
\hline $\begin{array}{l}\text { Borrowed used other injecting equipment } \\
\text { (i.e. water, filters, cookers, tourniquets, } \\
\text { swabs, acidifiers), past six months }\end{array}$ & 882 & 2,324 & 38.0 \\
\hline $\begin{array}{l}\text { Borrowed used other injecting equipment } \\
\text { from people known wellc, past six months }\end{array}$ & 710 & 856 & 82.9 \\
\hline $\begin{array}{l}\text { Borrowed used non-injection drug } \\
\text { paraphernalia (i.e. straws, dollar bills and } \\
\text { pipes), past six months }\end{array}$ & 1,153 & 2,059 & 56.0 \\
\hline $\begin{array}{l}\text { a Total represents total counts for the corresponding indicator excluding "don't know", "refused", } \\
\text { and "not stated" values } \\
\text { b This question was not asked at the London site } \\
\text { " People known well was defined as family, friends or sex partners }\end{array}$ & & \\
\hline
\end{tabular}

The proportion of participants who reported borrowing used needles and/or syringes decreased by almost half from $20.2 \%$ in Phase 1 and $21.8 \%$ in Phase 2 to $11.6 \%$ in Phase 4 . In contrast, the proportion who reported borrowing other used injection equipment (such as water, filter, cooker, spoons, tourniquets, ties, swabs and acidifiers) increased by almost a third from Phase 1 (29.8\%) to Phase 4 (38.0\%) (Supplemental table D).

\section{Drug use and overdose experiences}

In Phase 4, cocaine was the most commonly injected drug in the six months prior to the interview (60.0\%), followed by hydromorphone $(50.1 \%)$, methamphetamine (43.5\%), morphine (41.6\%) and heroin (32.4\%). Participants consumed a wide range of non-injection drugs over the same period, most frequently cannabis $(72.1 \%)$, alcohol $(62.5 \%)$, crack $(47.8 \%)$, cocaine (46.6\%) and methamphetamine (43.0\%). Opioid analgesic consumption (non-injection routes) was also reported specifically for methadone (35.0\%), hydromorphone (28.2\%), codeine (27.5\%), morphine (24.7\%), fentanyl (19.8\%), heroin $(19.7 \%)$ and oxycodone (15.6\%) (Table 5).

Among Phase 4 participants, the majority had heard of overdose kits (87.5\%) and reported that kits were available in their community (91.5\%); a lower proportion had ever used one on someone else (32.0\%). Nearly one-quarter (22.6\%) had overdosed in the six months prior to the interview and the drugs most commonly reported at last overdose were fentanyl (43.0\%), heroin $(38.3 \%)$, methamphetamine $(28.4 \%)$, cocaine $(23.1 \%)$ and alcohol (15.9\%) (Table 5).
Table 5: Drug use and experiences with overdoses of participants in the Tracks survey of people who inject drugs in Canada, Phase 4, 2017-2019 $(n=2,383)$

\begin{tabular}{|c|c|c|c|}
\hline $\begin{array}{c}\text { Drug use and experiences with } \\
\text { overdoses }\end{array}$ & $\mathbf{n}$ & Total $^{\mathrm{a}}$ & $\%$ \\
\hline \multicolumn{4}{|c|}{ Types of injection drugs used, past six months ${ }^{b}$} \\
\hline Cocaine & 1,419 & 2,364 & 60.0 \\
\hline Hydromorphone & 1,184 & 2,363 & 50.1 \\
\hline Methamphetamine & 1,027 & 2,360 & 43.5 \\
\hline Morphine & 982 & 2,362 & 41.6 \\
\hline Heroin & 764 & 2,357 & 32.4 \\
\hline Fentanyl & 572 & 2,350 & 24.3 \\
\hline Amphetamines & 506 & 2,358 & 21.5 \\
\hline Crack & 473 & 2,362 & 20.0 \\
\hline Ritalin alone & 466 & 2,361 & 19.7 \\
\hline Oxycodone & 400 & 2,365 & 16.9 \\
\hline Heroin and cocaine & 330 & 2,359 & 14.0 \\
\hline Benzodiazepines & 173 & 2,361 & 7.3 \\
\hline Talwin and Ritalin & 166 & 2,359 & 7.0 \\
\hline Methadone & 145 & 2,366 & 6.1 \\
\hline Other drugs ${ }^{c}$ & 237 & 1,751 & 13.5 \\
\hline \multicolumn{4}{|c|}{ Types of non-injection drugs used, past six months ${ }^{b}$} \\
\hline Cannabis & 1,698 & 2,356 & 72.1 \\
\hline Alcohol & 1,472 & 2,355 & 62.5 \\
\hline Crack & 1,125 & 2,352 & 47.8 \\
\hline Cocaine & 1,097 & 2,354 & 46.6 \\
\hline Methamphetamine & 1,010 & 2,349 & 43.0 \\
\hline Amphetamines & 836 & 2,348 & 35.6 \\
\hline Methadone & 824 & 2,357 & 35.0 \\
\hline Benzodiazepines & 705 & 2,349 & 30.0 \\
\hline Hydromorphone & 662 & 2,351 & 28.2 \\
\hline Codeine & 645 & 2,350 & 27.5 \\
\hline Morphine & 582 & 2,354 & 24.7 \\
\hline Fentanyl & 462 & 2,337 & 19.8 \\
\hline Heroin & 462 & 2,345 & 19.7 \\
\hline Oxycontin or Oxycodone & 367 & 2,347 & 15.6 \\
\hline Ecstasy & 223 & 2,351 & 9.5 \\
\hline Mushrooms & 214 & 2,350 & 9.1 \\
\hline Talwin and Ritalin & 213 & 2,352 & 9.1 \\
\hline Barbiturates & 200 & 2,345 & 8.5 \\
\hline Other drugs ${ }^{c}$ & 363 & 1,809 & 20.1 \\
\hline \multicolumn{4}{|c|}{ Awareness, access and use of an overdose kit ${ }^{d}$} \\
\hline Heard of overdose kits & 1,276 & 1,458 & 87.5 \\
\hline Ever used an overdose kit & 408 & 1,274 & 32.0 \\
\hline \multicolumn{4}{|c|}{ Overdose kits are available in participants' community } \\
\hline Yes & 1,168 & 1,212 & 91.5 \\
\hline No & 44 & 1,276 & 3.5 \\
\hline Don't know & 64 & 1,276 & 5.0 \\
\hline \multicolumn{4}{|l|}{ Overdose experiences } \\
\hline Overdosed in the past six months ${ }^{e}$ & 374 & 1,652 & 22.6 \\
\hline
\end{tabular}


Table 5: Drug use and experiences with overdoses of participants in the Tracks survey of people who inject drugs in Canada, Phase 4, 2017-2019 ( $n=2,383)$ (continued)

\begin{tabular}{|c|c|c|c|}
\hline $\begin{array}{c}\text { Drug use and experiences with } \\
\text { overdoses }\end{array}$ & $\mathbf{n}$ & Total $^{a}$ & $\%$ \\
\hline \multicolumn{4}{|l|}{ Drugs or substances used at last overdose $e^{b, d, f}$} \\
\hline Fentanyl & 128 & 298 & 43.0 \\
\hline Heroin & 116 & 303 & 38.3 \\
\hline Methamphetamine & 87 & 306 & 28.4 \\
\hline Cocaine & 71 & 308 & 23.1 \\
\hline Alcohol & 49 & 309 & 15.9 \\
\hline Cannabis & 40 & 307 & 13.0 \\
\hline Benzodiazepines & 35 & 305 & 11.5 \\
\hline Crack & 30 & 305 & 9.8 \\
\hline Morphine & 25 & 308 & 8.1 \\
\hline Methadone & 23 & 308 & 7.5 \\
\hline Hydromorphone & 20 & 308 & 6.5 \\
\hline Other drugs ${ }^{c}$ & 85 & 310 & 27.4 \\
\hline \multicolumn{4}{|c|}{$\begin{array}{l}\text { "Total represents total counts for the corresponding indicator excluding "don't know", "refused", } \\
\text { and "not stated" values } \\
\text { b Participants recorded all drugs (that they had injected, consumed or used at last overdose) for } \\
\text { non-medicinal purposes in the six months prior to interview. The most commonly reported drugs } \\
\text { among all participants are presented. Responses are non-mutually exclusive } \\
\text { c Other includes drugs with frequencies of less than } 5 \% \\
\text { d This question was not asked at the SurviDI network and London sites } \\
\text { e This question was not asked at the SurvUDI network sites } \\
\text { "Among participants who overdosed in the past six months and who provided a response }\end{array}$} \\
\hline
\end{tabular}

The drug most commonly injected across all phases was cocaine (60.0\%-81.6\%). Between Phase 1 and 4, there was an increasing trend in injecting hydromorphone (29.9\%-50.1\%), methamphetamine (6.8\%-43.5\%), fentanyl (1.7\%-24.3\%) and amphetamines (7.9\%-21.5\%). Across all phases, non-injection use of cannabis and alcohol stayed at high levels (Supplemental table D).

\section{Sexual risk behaviours}

In Phase 4, in the six months prior to the interview, among participants who had ever had sex, $35.2 \%$ had two or more sexual partners, $59.2 \%$ had inconsistent condom use during vaginal and/or anal sex with a casual sex partner, $84.9 \%$ had inconsistent condom use during vaginal and/or anal sex with a regular sex partner and $15.7 \%$ had engaged in transactional sex at least once (Table 6). Among those that engaged in transactional sex, $30.7 \%$ did not use condoms at last transactional sex. The majority of participants $(84.2 \%)$ reported substance use before or during sex (Table 6 ).

Across all phases, of participants who had ever had sex in the six months prior to the interview, the proportion who had two or more sex partners and who had engaged in transactional sex stayed relatively stable (Supplemental table D).
Table 6: Sexual risk behaviours of participants in the Tracks survey of people who inject drugs in Canada, Phase 4, 2017-2019 ( $n=2,383)$

\section{Sexual risk behaviours}

\section{\begin{tabular}{l|l|l} 
n & Total $^{\mathrm{a}}$ & $\%$ \\
\hline
\end{tabular}}

\begin{tabular}{|l|r|r|r|}
\hline Two or more sex partners, past six months $^{b}$ & 798 & 2,270 & 35.2 \\
\hline $\begin{array}{l}\text { Inconsistent condom use during vaginal and/ } \\
\text { or anal sex with a casual sex partner, past six } \\
\text { months }\end{array}$ & 413 & 698 & 59.2 \\
\hline $\begin{array}{l}\text { Inconsistent condom use during vaginal and/ } \\
\text { or anal sex with a regular sex partner, past six } \\
\text { months }^{c}\end{array}$ & 1,086 & 1,279 & 84.9 \\
\hline Engaged in transactional sex, past six months & 280 & 1,786 & 15.7 \\
\hline Condomless sex at last transactional sex $^{\mathrm{d}}$ & 66 & 215 & 30.7 \\
\hline $\begin{array}{l}\text { Substance use before or during sex, past six } \\
\text { months }^{\mathrm{d}}\end{array}$ & 1,088 & 1,292 & 84.2 \\
\hline
\end{tabular}

Total represents total counts for the corresponding indicator excluding "don't know", "refused", and "not stated" values

The denominator excludes participants who never had sex

Inconsistent condom use defined as not always using a condom (i.e. never, sometimes, or frequently). This question was not asked at the London site

This question was not asked at the SurvUDI network sites

\section{HIV and hepatitis C prevalence and awareness}

Based on the laboratory testing, HIV prevalence was $10.3 \%$ and of those who were HIV-positive, $82.9 \%$ were aware of their HIV-positive status (Table 7). The proportion who tested positive for hepatitis $C$ antibodies was $64.2 \%$, which is a measure of lifetime exposure to hepatitis $C$ infection. Many (36.9\%) were hepatitis C RNA-positive-an indicator of current hepatitis C infection—of whom, 50.1\% were aware of their hepatitis C RNA positive status. Among participants who provided a biological sample of sufficient quantity for testing for both HIV antibodies and HCV RNA, $4.7 \%$ were HIV-positive and hepatitis C RNA positive; $4.3 \%$ were HIV-positive and hepatitis C RNA negative; $32.3 \%$ were HIV-negative and hepatitis C RNA positive; and $58.7 \%$ were HIV-negative and hepatitis C RNA negative.

Over the 15-year period from Phase 1 to Phase 4, HIV prevalence decreased from $14.9 \%$ to $10.3 \%$. Among HIV-positive participants, the proportion of participants who were aware of their HIV-positive status increased slightly $(77.8 \%-82.9 \%)$. Across all phases, the proportion who tested positive for hepatitis $\mathrm{C}$ antibodies was relatively stable with about two-thirds $\mathrm{HCV}$ antibody positive (64.2\%-69.0\%) (Supplemental table D).

\section{HIV and hepatitis C care cascade}

Indicators measuring the HIV care cascade were examined among participants aware of their HIV-positive status (Table 7). The majority were under the care of a doctor or health care provider for HIV-related services at the time of the interview (95.0\%). The majority had also taken antiretroviral therapy (ART) (97.2\%) and were currently taking ART at the time of the interview (87.7\%). Adherence to ART, measured as no missed doses in the month prior to the interview, was $42.5 \%$. Among participants currently taking ART at the time of the interview, $62.8 \%$ reported an undetectable HIV viral load. Nearly half of all 
Table 7: HIV and hepatitis C prevalence, awareness of infection status, and care cascade of participants in the Tracks survey of people who inject drugs in Canada, Phase 4, 2017-2019 $(n=2,383)$

\begin{tabular}{|c|c|c|c|}
\hline HIV and hepatitis $C$ prevalence & $\mathbf{n}$ & Total $^{\mathrm{a}}$ & $\%$ \\
\hline \multicolumn{4}{|l|}{ HIV prevalence and awareness of infection status } \\
\hline HIV prevalence ${ }^{b, c}$ & 222 & 2,162 & 10.3 \\
\hline Awareness of HIV-positive status ${ }^{d}$ & 179 & 216 & 82.9 \\
\hline \multicolumn{4}{|c|}{$\begin{array}{l}\text { HIV care cascade (among participants aware of their } \\
\text { HIV-positive status, } n=179 \text { ) }\end{array}$} \\
\hline Linkage to care for HIV-related services ${ }^{e}$ & 170 & 179 & 95.0 \\
\hline Ever taken ART treatment & 174 & 179 & 97.2 \\
\hline Currently taking ART treatment & 157 & 179 & 87.7 \\
\hline $\begin{array}{l}\text { Adherence to ART, no missed doses in last } \\
\text { month }^{f}\end{array}$ & 34 & 80 & 42.5 \\
\hline Self-reported undetectable HIV viral loadg & 59 & 94 & 62.8 \\
\hline $\begin{array}{l}\text { Avoidance of HIV services because of stigma } \\
\text { and discrimination, past } 12 \text { months }\end{array}$ & 43 & 95 & 45.3 \\
\hline \multicolumn{4}{|c|}{ Hepatitis C prevalence and awareness of infection status } \\
\hline HCV antibody prevalence ${ }^{c, h}$ & 1,375 & 2,141 & 64.2 \\
\hline HCV RNA prevalence ${ }^{c, i}$ & 486 & 1,316 & 36.9 \\
\hline $\begin{array}{l}\text { Awareness of hepatitis C RNA positive } \\
\text { status }\end{array}$ & 238 & 475 & 50.1 \\
\hline
\end{tabular}

Hepatitis $C$ care cascade (among participants aware of their hepatitis $C$ RNA-positive status, $n=238$ )

\begin{tabular}{|c|c|c|c|}
\hline Linkage to care for hepatitis $C^{k}$ & 115 & 237 & 48.5 \\
\hline Ever taken hepatitis $C$ treatment ${ }^{\prime}$ & 25 & 236 & 10.6 \\
\hline Currently taking hepatitis $C$ treatment & 9 & 236 & 3.8 \\
\hline
\end{tabular}

\section{HIV and hepatitis $C$ coinfection ${ }^{m}$}

\begin{tabular}{|l|r|r|r|}
\hline HIV-positive and hepatitis C RNA positive & 62 & 1,314 & 4.7 \\
\hline HIV-positive and hepatitis C RNA negative & 57 & 1,314 & 4.3 \\
\hline HIV-negative and hepatitis C RNA positive & 424 & 1,314 & 32.3 \\
\hline HIV-negative and hepatitis C RNA negative & 771 & 1,314 & 58.7 \\
\hline
\end{tabular}

Abbreviations: ART, anti-retroviral therapy; $\mathrm{HCV}$, hepatitis $\mathrm{C}$ virus; HIV, human immunodeficiency virus; RNA, ribonucleic acid

a Total represents total counts for the corresponding indicator, excluding "don't know", "refused", and "not stated" values

${ }^{b}$ Among participants who provided a biological sample of sufficient quantity for HIV testing ' HIV and hepatitis $\mathrm{C}$ testing algorithms are provided in Appendix 2

d Among participants who tested positive for HIV antibodies and who reported their HIV

diagnosis. Participants who reported that their last HIV test result was positive and who wer

diagnosis. Participants who reported that their last HIV test result was positive and who were
found to be HIV positive based on testing of the biological specimen provided at the time of

interview were classified as being aware of their HIV positive status

e Defined as under the care of a doctor or health care provider for HIV-related services at the time

of the interview (in the six months prior to the interview in the SurvUDI network and London sites) ${ }^{f}$ This question was not asked at the SurvUDI network $(n=65)$ and London sites $(n=17)$. The denominator also excludes participants with missing data

9 Among participants currently on ART treatment at the time of the interview. This question was not asked at the SurvUDI network sites $(n=62)$. The denominator also excludes participants with missing data

${ }^{\mathrm{h}}$ Among participants who provided a biological sample of sufficient quantity for HCV antibody testing

Among participants who provided a biological sample of sufficient quantity for $\mathrm{HCV}$ antibody and RNA testing. HCV RNA testing was not conducted at the SurvUDI network sites

Among participants who tested HCV RNA positive and who reported their current hepatitis $C$ status. Participants who reported being currently infected with hepatitis $C$ and who were hepatitis C RNA positive based on testing of the biological specimen provided at the time of interview were classified as being aware of their hepatitis C RNA positive status

${ }^{k}$ Defined as under the care of a health care provider for hepatitis C-related services at the time of the interview. The denominator excludes participants with missing data

The denominator excludes participants with missing data

${ }^{m}$ Among participants who provided a biological sample of sufficient quantity for testing for both HIV antibodies and HCV RNA testing. HCV RNA testing was not conducted at the SurvUDI network sites participants who were aware of their HIV-positive status reported avoiding HIV services because of stigma and discrimination in the 12 months prior to the interview (45.3\%).

Indicators measuring the hepatitis $C$ care cascade were examined among participants who were aware of their current hepatitis $C$ infection (Table 7). Nearly half (48.5\%) reported being linked to care for hepatitis C; a smaller proportion (10.6\%) had ever taken hepatitis $C$ treatment; and an even smaller proportion (3.8\%) were currently taking hepatitis $C$ treatment.

From Phase 1 to Phase 4, among participants aware of their HIVpositive status, linkage to care for HIV-related services increased (88.1\%-95.0\%) as did the proportion of those currently taking ART treatment (52.0\%-87.7\%). Across all phases, only about half of the participants who were aware of their hepatitis $C$ infection status were under the care of a doctor for their hepatitis $C$ infection and the proportion currently taking hepatitis $C$ treatment was very low (Supplemental table D).

\section{Discussion}

People who inject drugs represent an important risk group in Canada's HIV and hepatitis C epidemics (1). Information gathered from the Tracks survey of PWID in Canada help contextualize the epidemiology of HIV, hepatitis C and associated risk behaviours among this population, providing comparisons over time and new baseline data on key emerging indicators, such as experiences of stigma and discrimination, overdoses and the use of PrEP. Factors associated with increased vulnerability to HIV and hepatitis $C$ in previous studies were also identified among this survey sample of PWID. Markers of poverty and marginalization, including high numbers living in unstable housing and/or ever incarcerated, were common. Lived experience of stigma and discrimination, as well as physical, sexual and/or emotional abuse (in childhood or with a sexual partner), were also identified by the majority of participants.

High rates of testing for HIV and hepatitis $C$ and the use of needle and syringe distribution programs were noted. However, access to other key harm reduction services was lower, with less than half of the participants reporting the use of opioid-substitution therapy or the use of a supervised injection or consumption site in the previous year. Drug use and injecting behaviours reported in Phase 4 signalled important proportions of participants who borrow needles and/or syringes and other used injecting equipment. The majority of participants (59.2\%) reported inconsistent condom use with a casual sex partner and $84.2 \%$ reported substance use before or during sex, both of which are associated with the transmission of STBBI including syphilis. Preexposure prophylaxis awareness was low among participants (14.3\%), and the use of PrEP was only $0.3 \%$ among those who did not report an HIV-positive diagnosis. 
Many of the national surveillance findings are consistent with the findings from other integrated bio-behavioural surveillance systems with comparable HIV and hepatitis $C$ epidemics. Specifically, among PWID surveyed in the United States, Australia and the United Kingdom, similar levels of prevention and testing indicators (i.e. testing for HIV and hepatitis $C$, use of opioid substitution therapy), injecting behaviours (i.e. borrowing used needles and/or syringes, borrowing used other injection equipment) and sexual practices (i.e. transactional sex, condomless sex) were found (6-8). Previous regional studies among PWID in Canada have also found similar levels of unstable housing $(9,10)$, and high proportions who have experienced violence $(10)$, and abuse $(9,10)$.

The ongoing opioid crisis and other drug-related overdose deaths have greatly affected the population of PWID in Canada. Increased use of methamphetamine, fentanyl and opioid analgesics found among Phase 4 participants echo this alarming trend. Phase 4 surveillance findings provided information regarding new overdose-related indicators. While awareness and access of overdose kits was high, $22.6 \%$ had overdosed in the six months prior to the interview with fentanyl and heroin the most commonly reported drugs used at last overdose.

While HIV prevalence among Phase 4 participants (10.3\%) had decreased since Phase 1 (conducted in 2003-2005) it was nevertheless high-nearly 10-fold higher compared with rates among PWID in Australia and the United Kingdom $(7,8)$. A slightly higher proportion of participants were aware of their HIV-positive status in Phase 4 (82.9\%) compared with the previous phases. For the first time, hepatitis C RNA prevalence was measured in the Tracks survey of PWID and found to be high (36.9\%). In addition, only $50.1 \%$ of participants were aware of their hepatitis C RNA-positive status (i.e. current hepatitis C infection).

Nearly all participants who were aware of their HIV-positive status were linked to care for HIV-related services and were currently taking ART; however, less than two-thirds (62.8\%) reported an undetectable viral load and $45.3 \%$ reported avoiding HIV services because of experienced stigma and discrimination. Much lower rates for linkage to care (48.5\%) and current treatment use $(3.8 \%)$ were found among participants who self-reported current infection with hepatitis $C$. Low numbers of PWID who are linked to hepatitis care and treatment have been observed in other regional studies in Canada (11).

The results from the Phase 4 Tracks survey of PWID can inform evidence-based strategies to address gaps in prevention, testing and linkage to care approaches. This can include better linkage to opioid substitution therapy and supervised injection or consumption sites, and improve access to health and social services for mental health and addictions (12). The confluence of high rates of hepatitis $C$ combined poor awareness, continued but reduced needle sharing and inconsistent condom use despite increased rates of program uptake highlights the need harm reduction programs to continue to evolve to meet these challenges.

\section{Strengths and limitations}

The Tracks survey of PWID is a rich source of information on HIV and hepatitis $C$ among PWID from sites across the country, and provides trends on key indicators since 2003. Notably, it is the only national source of such information, and has been used at the local, provincial and federal levels to inform and guide public health interventions in this population. However, it is important to note that the Tracks survey uses non-probability-based sampling; therefore, findings may not be representative of all PWID at any given site or in Canada. With the exception of the laboratory results, these findings were based on interviewer-administered questionnaires and self-reported data and it is possible that certain risk behaviours were over- or underrepresented.

\section{Conclusion}

High levels of unstable housing, experienced stigma and discrimination, borrowing of used injection equipment and inconsistent condom use were found. Both HIV prevalence and hepatitis C RNA-positive prevalence is high among PWID in some areas of Canada. Important gaps related to linkage to care and treatment for hepatitis $C$ were identified. These findings highlight the need for: continued access to testing and prevention services, targeted strategies to address barriers to accessing HIV and hepatitis $C$ treatment and care and improvements in ongoing supports for housing, mental health and addictions.

\section{Authors' statement}

JT - Conceptualization, formal analysis, methodology, project administration, writing (original draft and review and editing) JZ - Conceptualization, data curation, formal analysis, writing (original draft and review and editing)

$\mathrm{AL}$ - Conceptualization, formal analysis, writing (review and editing)

FC - Conceptualization, methodology, writing (review and editing)

MB - Conceptualization, methodology, project administration, writing (review and editing)

DP - Conceptualization, funding acquisition, methodology, writing (review and editing)

\section{Conflict of interest}

None.

\section{Acknowledgements}

The Tracks Surveillance System is possible because of the successful collaboration between the Public Health Agency of Canada (including the National Microbiology Laboratory), and 
provincial, regional and local health authorities, researchers and community-based organizations. The authors gratefully acknowledge the contribution of the participants, the sentinel site teams, including survey coordinators and interviewers, and the site principal investigators: M Alary; K Chokani; J DeMille; B Enns; M Gully; B Hanley; M Hennink; P Leclerc; C Mackie; S Marshall; C Morissette; É Roy; S Shaw; C Smith; A Vanderlaan; and D Warren. The authors would also like to thank $C$ Archibald for his advice prior to and throughout data collection and for his review of the manuscript and $C$ Daniuk for her support with the dried blood spot testing.

\section{Funding}

The Tracks survey of people who inject drugs in Canada is supported by the Public Health Agency of Canada, with in-kind contributions provided by regional and local health authorities and community-based organizations.

\section{References}

1. Public Health Agency of Canada. Summary: Estimates of HIV Incidence, Prevalence and Canada's Progress on Meeting the 90-90-90 HIV Targets, 2016. Government of Canada; 2018. https://www.canada.ca/content/dam/phac-aspc/ documents/services/publications/diseases-conditions/ summary-estimates-hiv-incidence-prevalence-canadasprogress-90-90-90/pub-eng.pdf

2. Degenhardt L, Charlson F, Stanaway J, Larney S, Alexander LT, Hickman M, Cowie B, Hall WD, Strang J, Whiteford H, Vos T. Estimating the burden of disease attributable to injecting drug use as a risk factor for HIV, hepatitis C, and hepatitis B: findings from the Global Burden of Disease Study 2013. Lancet Infect Dis 2016;16(12):1385-98. DOI PubMed

3. Public Health Agency of Canada. I-Track: Enhanced Surveillance of HIV, Hepatitis C, and Associated Risk Behaviours Among People Who Inject Drugs in Canada - Phase 3 (2010-2012) Report. Government of Canada; 2018. https://www.canada.ca/en/public-health/services/ publications/diseases-conditions/itrack-enhance d-surveillance-hiv-hepatitis-associated-risk-beh aviours-people-who-inject-drugs-canada-phase-3.html

4. World Health Organization/UNAIDS. Guidelines on surveillance among populations most at risk for HIV. Geneva: WHO; 2011. http://files.unaids.org/en/media/unaids/ contentassets/documents/epidemiology/2011/20110518_ Surveillance_among_most_at_risk.pdf
5. Leclerc P, Roy É, Morissette C, Alary M, Parent R, Blouin K. Surveillance des maladies infectieuses chez les utilisateurs de drogues par injection - Épidémiologie du VIH de 1995 à 2014 - Épidémiologie du VHC de 2003 à 2016. Institut national de santé publique du Québec; 2018. https:// www.inspq.qc.ca/sites/default/files/publications/2400_ surveillance_maladies_infectieuses_utilisateurs_drogue_ injection.pdf

6. Centers for Disease Control and Prevention. HIV Infection, Risk, Prevention, and Testing Behaviors among Persons Who Inject Drugs-National HIV Behavioral Surveillance: Injection Drug Use, 20 U.S. Cities, 2015. Atlanta (GA); CDC: 2018. https://www.cdc.gov/hiv/pdf/library/reports/surveillance/ cdc-hiv-hssr-nhbs-pwid-2015.pdf

7. Heard S, Iversen J, Geddes L, Maher L. Australian Needle Syringe Program Survey National Data Report 2014-2018: Prevalence of HIV, HCV and injecting and sexual behaviour among NSP attendees. Sydney (NSW): Kirby Institute, UNSW Sydney; 2019. https://kirby.unsw.edu.au/sites/default/files/ kirby/report/ANSPS_National-Data-Report-2014-2018.pdf

8. Public Health England. Unlinked Anonymous Monitoring (UAM) Survey of HIV and viral hepatitis among PWID: 2019 report. London (UK): PHE; 2019. https://assets.publishing. service.gov.uk/government/uploads/system/uploads/ attachment_data/file/825117/hpr2919_UAM-PWID.pdf

9. Miller $\mathrm{CL}$, Pearce ME, Moniruzzaman A, Thomas $\mathrm{V}$, Christian CW, Schechter MT, Spittal PM. The Cedar Project: risk factors for transition to injection drug use among young, urban Aboriginal people. CMAJ. July 12, 2011; 183(10): 1147-54. DOI

10. Dong H, Hayashi K, Singer J, Milloy MJ, DeBeck K, Wood E, Kerr T. Trajectories of injection drug use among people who use drugs in Vancouver, Canada, 1996-2017: growth mixture modeling using data from prospective cohort studies. Addiction 2019;114(12):2173-86. DOl PubMed

11. Socías ME, Ti L, Wood E, Nosova E, Hull M, Hayashi K, Debeck K, Milloy MJ. Disparities in uptake of direct-acting antiviral therapy for hepatitis $\mathrm{C}$ among people who inject drugs in a Canadian setting. Liver Int 2019;39(8):1400-7. DOI PubMed

12. Public Health Agency of Canada. A pan-Canadian framework for action: Reducing the health impact of sexually transmitted and blood-borne infections in Canada by 2030. Government of Canada; 2018. https://www.canada.ca/content/dam/ phac-aspc/documents/services/infectious-diseases/ sexual-health-sexually-transmitted-infections/ reports-publications/sexually-transmitted-blood-born e-infections-action-framework/sexually-transmitte d-blood-borne-infections-action-framework.pdf 


\section{Appendices}

Appendix 1: Tracks survey of people who inject drugs in Canada - total number of participants and sentinel site participation, Phase 1 to Phase 4

Appendix 2: HIV and hepatitis $\mathrm{C}$ testing algorithms

\section{Supplementary tables}

Table A: Prevention and testing indicators by socio-demographic characteristics and social determinants of health of participants in the Tracks survey of people who inject drugs in Canada, Phase 4, 2017-2019 $(n=2,383)$

Table B: Injecting behaviours and drug use indicators by sociodemographic characteristics and social determinants of health of participants in the Tracks survey of people who inject drugs in Canada, Phase 4, 2017-2019 ( $n=2,383)$

Table C: Sexual risk behaviour indicators by socio-demographic characteristics and social determinants of health of participants in the Tracks survey of people who inject drugs in Canada, Phase 4, 2017-2019 ( $n=2,383)$

Table D: Selected indicators by phase of the Tracks survey of people who inject drugs in Canada, Phase 1 to 4, 2003-2019

\section{Appendix 1: Tracks survey of people who inject drugs in Canada - total number of participants and sentinel site participation, Phase 1 to Phase 4}

\begin{tabular}{|c|c|c|c|c|}
\hline Phase details & $\begin{array}{c}\text { Phase } 1 \\
2003-2005\end{array}$ & $\begin{array}{c}\text { Phase } 2 \\
2005-2008\end{array}$ & $\begin{array}{c}\text { Phase } 3 \\
2010-2012\end{array}$ & $\begin{array}{c}\text { Phase } 4 \\
2017-2019\end{array}$ \\
\hline Total number of participants & 2,986 & 2,982 & 2,687 & 2,383 \\
\hline Number of sentinel sites & 7 & 10 & 11 & 14 \\
\hline \multicolumn{5}{|l|}{ Sentinel site } \\
\hline Whitehorse, YK & - & - & 55 & 49 \\
\hline Central and Northern Vancouver Island, BC & - & 220 & - & 179 \\
\hline Victoria, BC & 253 & 249 & - & - \\
\hline Prince George, BC & - & 156 & 150 & - \\
\hline Edmonton, $A B$ & 272 & 248 & 183 & - \\
\hline Prince Albert, SK & - & - & - & 184 \\
\hline Regina, SK & 250 & 250 & 251 & 205 \\
\hline Winnipeg, MB & 245 & - & - & 181 \\
\hline Thunder Bay, ON & - & 149 & 138 & 200 \\
\hline Sudbury, ON & 150 & 147 & 148 & - \\
\hline London, ON & - & - & 204 & 206 \\
\hline Hamilton, ON & - & - & - & 157 \\
\hline Toronto, ON & 257 & 255 & 260 & - \\
\hline Kingston, ON & - & 224 & 200 & - \\
\hline SurvUDI network, QCa & 1,559 & 1,084 & 937 & $692^{b}$ \\
\hline New Brunswick & - & - & - & 200 \\
\hline Halifax, NS & - & - & 161 & - \\
\hline Newfoundland & - & - & - & 130 \\
\hline
\end{tabular}




\section{Appendix 2: HIV and hepatitis C testing algorithms}

\section{HIV testing algorithms}

For non-SurvUDI sites, HIV status was initially determined by screening dried blood spot specimens using the Bio-Rad GS HIV Combo Ag/Ab assay followed by confirmatory testing using the Roche COBAS AmpliPrep/COBAS Taqman HIV-1 Quant v2.0 assay (London) or the Roche COBAS AmpliPrep/COBAS Taqman HIV-1 Qualitative Test v2.0 (New Brunswick, Newfoundland and Regina). For the remaining non-SurvUDI sites (i.e. Vancouver Island, Thunder Bay, Whitehorse, Winnipeg, Prince Albert and Hamilton), due to recurrent low volume specimens, HIV status was determined by performing screening and confirmatory testing using two separate enzyme immunoassays (EIAs). As a result, specimen volume was sufficient for HIV and hepatitis $C$ testing in most cases. The change in algorithms is not expected to have an impact on the results. Algorithms are described in more detail below.

London: HIV screening was performed using the Bio-Rad GS HIV Combo Ag/Ab assay. A non-reactive result indicated no HIV infection. Confirmatory testing was performed on screened reactive results using the Roche COBAS AmpliPrep/COBAS Taqman HIV1 Quant v2.0 assay. A detected result indicated a HIV infection. In instances where the Bio-Rad GS HIV Combo Ag/Ab assay was positive, and the Roche COBAS ApliPrep/COBAS Taqman HIV-1 v2.0 assay result was not detected, a second EIA (AVIOQ HIV-1 Microelisa System) was conducted. A reactive result on both the Bio-Rad GS HIV Combo Ag/Ab assay and the AVIOQ HIV-1 Microelisa System indicated an HIV infection.

New Brunswick, Newfoundland and Regina: HIV screening was performed using the Bio-Rad GS HIV Combo Ag/Ab assay (BioRad). A non-reactive result indicated no HIV infection. Confirmatory testing was performed on screened reactive results using the Roche COBAS AmpliPrep/COBAS Taqman HIV-1 Qualitative Test v2.0 (Roche). A detected result indicated an HIV infection. In instances where the Bio-Rad was reactive, and the Roche result was not detected, a second EIA, the AVIOQ HIV-1 Microelisa System (Avioq), was conducted as a tie-breaker. A reactive result on both the Bio-Rad and the Aviog indicated an HIV infection. A reactive result on the Bio-Rad, not detected result on the Roche, and a non-reactive or an indeterminate (i.e. absorbance results that were near, but did not overlap, the cut-off value for a reactive/non-reactive result) result on the Avioq, was interpreted as an overall indeterminate result.

Vancouver Island, Thunder Bay, Whitehorse, Winnipeg, Prince Albert, and Hamilton: HIV screening was performed using the BioRad GS HIV Combo Ag/Ab assay (Bio-Rad). A non-reactive result indicated no HIV infection. Confirmatory testing was performed on screened reactive results using a second EIA, the AVIOQ HIV1 Microelisa System (Avioq). A reactive result indicated an HIV infection. In instances where the Bio-Rad was reactive, and the Aviog was non-reactive or indeterminate (i.e. absorbance results that were near, but did not overlap, the cut-off value for a reactive/nonreactive result), the Roche COBAS AmpliPrep/COBAS Taqman HIV-1 Qualitative Test v2.0 (Roche) was used as a tie-breaker. A reactive result on the Bio-Rad and a detected result on the Roche indicated an HIV infection. A reactive result on the Bio-Rad, non-reactive or indeterminate result on the Avioq, and a not detected result on the Roche, was interpreted as an overall indeterminate result.

For SurvUDI network sites, oral fluid specimens were screened for HIV at the Laboratoire de santé publique du Québec, Institut national de santé publique du Québec, using the Bio-Rad GS HIV1/HIV2 PLUS O EIA, a diagnostic assay approved by Health Canada and validated in the SurvUDI study for use with oral fluid. Confirmatory testing was not performed for samples that tested repeatedly reactive. A positive result indicated an HIV infection.

\section{Hepatitis $\mathrm{C}$ testing algorithms}

For all non-SurvUDI network sites: hepatitis $C$ screening testing was performed using the Ortho ${ }^{\circledR} \mathrm{HCV}$ version 3.0 EIA (Ortho).

A non-reactive result indicated never having been infected with hepatitis $C$. A reactive result indicated lifetime exposure to hepatitis C. Confirmatory testing was performed on screened reactive and indeterminate results (i.e. absorbance results that were near, but did not overlap, the cut-off value for a reactive/non-reactive result) using the Roche COBAS AmpliPrep/COBAS Taqman HCV Quantitative test v2.0 (Roche). A detected result indicated a current hepatitis $C$ infection and a not detected result indicated a lifetime exposure to hepatitis $C$. For those that screened indeterminate on the Ortho, a detected result on the Roche indicated a current hepatitis $C$ infection and a not detected result on the Roche was interpreted as an indeterminate result.

SurvUDI network sites: hepatitis $C$ antibody testing for oral fluid specimens was performed using the Ortho ${ }^{\circledR}$ hepatitis $C$ version 3.0 EIA at the Institut national de santé publique du Québec laboratories. Confirmatory testing was not performed for samples that tested positive. A positive result indicated past or present hepatitis $C$ infection and did not discriminate acute from chronic or resolved infections. Validation of this test for use with oral fluid was performed in the SurvUDI study.

\section{Sensitivity and specificity of laboratory tests} The specificity of the Bio-Rad GS HIV Combo Ag/Ab EIA, Avioq HIV1 Microelisa System, and Roche COBAS AmpliPrep/COBAS TaqMan HIV-1 Qualitative Test v2.0 is $\geq 99.9 \%$ on DBS according to kit inserts or internal validation data. Similarly, the sensitivity of each assay is $100 \%$ except for the Bio-Rad GS HIV Combo Ag/Ab EIA which is $96.6 \%$. The limit of quantification for the Roche COBAS/AmpliPrep TaqMan HIV-1 Quantitative Test v2.0 on DBS is 616 copies $/ \mathrm{mL}$.

The specificity and sensitivity of the ORTHO HCV v3.0 ELISA Test System is $100 \%$ according to internal validation data. The limit of quantification for the Roche COBAS AmpliPrep/COBAS TaqMan HCV Test v2.0 is $355 \mathrm{IU} / \mathrm{mL}$. 